Article

\title{
Making Sustainable Regional Design Strategies Successful
}

\author{
Anastasia Nikologianni ${ }^{1, *}$, Kathryn Moore ${ }^{1} \mathbb{D}$ and Peter J. Larkham ${ }^{2}$ \\ 1 School of Architecture and Design, Birmingham City University, City Centre Campus, \\ B4 7BD Birmingham, UK; kathryn.moore@bcu.ac.uk \\ 2 School of Engineering and the Built Environment, Birmingham City University, B4 7BD Birmingham, UK; \\ peter.larkham@bcu.ac.uk \\ * Correspondence: natasa.nikologianni@gmail.com; Tel.: +44-(0)-7557386272
}

Received: 18 December 2018; Accepted: 8 February 2019; Published: 16 February 2019

\begin{abstract}
This paper identifies innovative methods of strategic spatial design to demonstrate the sustainable outcomes that can be achieved by adopting landscape practices to future-proof our cities and regions. A range of strategic landscape-led models and methodologies are investigated to reveal the structure, administrative processes and key elements that have been adopted in order to facilitate the integration of climate change environmental design and landscape quality. We have found that a strong established framework that demonstrates innovative project management and early integration of environmental ideas is critical in order to be able to deliver landscape schemes that appropriately identify and address current climatic and social challenges. Furthermore, to make a real difference in the way that professional practice and politics deal with landscape infrastructure, the project framework and key concepts related to landscape design and planning, such as low carbon design and spatial quality, need to be clearly supported by legislation and policy at all levels. Together with close attention to the importance of design, this approach is more likely to ensure effective implementation and smooth communication during the development of a landscape scheme, leading to higher levels of sustainability and resilience in the future.
\end{abstract}

Keywords: sustainability; landscape design; low carbon landscape; climate change; policy; strategic planning; adaptation; sustainable development; environmental planning

\section{Introduction}

In the era of globalisation and environmental instability the 'landscape' is often perceived as a medium of little importance compared to the global challenges we face, often missing the vulnerability of the landscape and its inhabitants to climate-related extremes. Regional- and strategic-scale schemes are often conceptualized, established and delivered by the project management or administration, controlled by governmental institutions. They often follow a 'common' and 'conventional' process of management and delivery, and it seems to be only when there is multidisciplinary interest and a pressure for a low-carbon and sustainable vision that an alternative, tailor-made project framework is likely to emerge. This 'conventional' thinking has resulted in frameworks that often focus only on the delivery of a specific engineering or low carbon challenge (e.g., emissions, constructions). A tailored framework as introduced by this research aims to offer an integrated approach to landscape values, considering economic, cultural and social characteristics with the aim of resulting in a sustainable lifestyle as this is defined by a specific location. It is simply an offer of a broader concept and exploration and not a single-sided view of a strategic development. This paper has been developed through the lens of environmental challenges, examining the opportunities for a changing climate to drive regional 
design and planning through the analysis of the structural, administrative and policy aspects of pioneer case studies.

Supporting the notion that landscape is "an area as perceived by people whose character is the result of the action and interaction of natural and/or human factors" [1] as proposed by the European Landscape Convention (ELC) this paper focuses on processes that enhance adaptation and climate awareness through landscape developments, and investigates schemes which have demonstrated their benefits. A number of innovative landscape projects across Europe are explored to identify and review the pioneer ways, timeframes, organizational models and ecological targets adopted to help to deliver sustainable regional design. The projects have developed individual processes and, through a series of methods, they have managed to address the landscape in a way differing from past planning and infrastructure methods. The full research is reported in Nikologianni [2].

Globally recognised projects were selected based on their innovative concepts and project processes as well as their significance in the academic discipline and professional practice, the integrated approach to sustainable management, their impact on landscape policy and, in some cases, the coherent planning and design concept. The Landscape Observatory (Catalonia), the Room for the River-New Dutch Waterline (The Netherlands) and the High Speed 2-Landscape Vision (HS2LV-UK) are used to explore these processes and methods, and how they diverge from common practice: the cross-disciplinary approaches and the careful exploration of ideas and successful project stories developed in different countries are important areas of investigation. The extended knowledge that the Landscape Observatory provides for the Catalan landscape, the technical and socio-cultural elements that are extracted from the climate adaptation schemes in The Netherlands and the way in which regional design can change perceptions on sustainable developments in the UK (HS2LV) justify the selection of these schemes for such a research. The case studies are not compared; each has stronger elements in different parts of a successful integration of sustainable ideas (e.g., in legislation, climate adaptation, awareness, decision making) and, therefore, best practices from each of them are extracted. Building strong connections with these innovative projects, the paper reveals the ways of thinking and the development processes in regional landscape schemes, extracting the expertise of three different countries; Spain, The Netherlands and the UK. These pioneer European landscape-based projects have demonstrated new ways of engaging with both climate and quality elements during the conceptual and implementation phase, and this study identifies innovative and best practices. The examination of the project processes and 'tailored' frameworks of the case studies has shown how landscape design can change perceptions and the way in which sustainable development can provide beneficial outcomes for people, nature and society through design and planning.

\section{Materials and Methods}

The main methodological stages link to a broader concept and are separated into three main themes. They are described as 'Identification', 'Socialization', and 'Implementation', and are attached to different case studies, aiming to reveal a series of data related to sustainable and high-quality transitions in landscape spatial strategies. A pilot study and the three case studies were chosen to reflect these different stages from identifying an idea, disseminating and implementing a landscape project in a large-scale. The research reviewed the lifecycle of the projects as far as possible. The Identification phase sought to identify low carbon and design objectives in current practice and the ways in which these are understood and interpreted by the experts in the field. This paper only uses preliminary data of this study, focusing instead on the other two phases. The Socialization phase was related to the case study of the Landscape Observatory, examining how landscape ideas were disseminated and how values and social engagement have impacted on the landscape. This was followed by the Implementation phase where the mechanism of a sustainable regional scheme was unpacked in order to reveal how such a process is possible and identify the necessary steps for this type of development in order to consider a regional strategy as sustainable. 
Following research on the background and establishment for the case studies, the research methods included field visits, interviews and observations with detailed examination of a wide range of documentation and publications relating to each project as well as expertise gained at the project locations. Semi-structured interviews with key actors engaged with the schemes, observation of meetings, participation in project activities and interaction with stakeholders benefiting from such concepts have generated useful insights on how a strategic landscape scheme is addressed in relation to climate challenges. The methodology included the main researcher being embedded within each project for one month during 2015. During this time, research was conducted at the headquarters of the projects, several field visits were scheduled for all the schemes and between 8-10 interviews with experts were arranged in each location. The interviews were based on semi-structured questionnaires and lasted from one to two hours, although interviews that included field visits lasted longer. The questionnaires were structured around two themes. The first set covered the ideas of landscape and sustainability and the second set focused on the specific project for each interviewee, the project's scope, structure, design approach and goals. A discussion about the representation of environmental ideas in the project, and how such issues were addressed, occurred in most cases. The interviewees selected represented a wide range of professionals in different positions and institutions of each country. They belong to various disciplines and have worked with the concepts of sustainability and landscape quality dealing with landscape awareness. Observations recorded through photographs, sketches and the researcher's notes have played a significant role in understanding how the landscape is integrated within the region and the surrounding cities. Further exploration of the schemes with the interviewees (though visits and drawings) have facilitated in-depth understanding of the structure and framework followed within the projects, as well as the key elements embedded for a sustainable implementation.

\section{Data Collection}

The data collection was based on both graphic visuals (drawings, maps, diagrams) and observations. Documents, maps, visual material, technical documents, case study notes, drawings and images of sustainable approaches as well as interview transcripts and recordings from the expert professionals were collected and analysed.

\section{Landscape as the Core Element of Spatial Design}

According to the European Landscape Convention (ELC), the landscape is closely associated with people and their interaction with both nature and man-made infrastructure [1]. As a result, human perception is closely related with the landscape and, therefore, it is reasonable to assume that strategic infrastructure development would align with that. Yet at present, for some reason, the concepts of landscape and spatial development are treated individually with little consideration of how one affects the other. Therefore, before this paper introduces the concepts of environmental landscape and sustainability, the idea of landscape and its significance in large-scale schemes needs exploration.

As Cosgrove suggests, "landscape is a way of seeing that has its own history, but a history that can be understood only as part of a wider history of economy and society; [ . . . ] that has its own techniques of expression" [3]. The bond with the land is important in the development of regional strategies, and so too is the bond with human groups, and their historical, social and cultural characteristics. Therefore, the first step towards the realisation of a spatial strategy is to understand its core element, the landscape and its symbiotic relationship with the environmental and socio-economic factors. Shannon and Smets [4] suggest that "infrastructural development is not merely a technical matter to be left to traffic planners, engineers, and politicians, but a crosscutting field that involves multiple sectors and where the role of designer is essential", embracing the importance of quality and the impact that this can have on the landscape. Bélanger [5] highlights the need to formulate landscape as an "infrastructural field of practice" and, in order to achieve this field of practice, the only way is to rethink infrastructure ecologically as an "open system of live media" instead of a closed, mechanical and engineered system. The changes in the current environmental, economic and political agenda 
transform the existing infrastructure development practices from purely technical and engineering activities to economic proposals with greater benefits for economy and the environment. Current examples, such as the creation of "enhanced metropolitan landscapes and cultural heritage" [6] or sustainably focused spatial schemes, enhance the notion that landscape needs to be reformulated "as a sophisticated, instrumental system of essential resources, services and agents" [7] that demonstrates the relationship between the land, the environment, the society and economy.

Thinking, designing, working and envisioning at a landscape scale is not easy, because the scale is sometimes irrelevant when it comes to addressing climate change, but highly relevant when dealing with policy, construction and other practical issues. As Meijsmans et al. [8] observe, operating at a strategic level becomes "increasingly important in tackling spatial questions and larger scale decisions" in an efficient way. It is crucial to acknowledge that human-defined scales often do not tackle climate change phenomena, and therefore large-scale landscape schemes need to develop a flexible interpretation of the 'landscape scale'.

\subsection{The Relationship between Low Carbon and the Landscape}

The elaboration of the concepts of climate adaptation, mitigation, land use, behavioural change and a resilient way of living, recognizing climate change as a concern that urgently needs to be addressed [9], emphasizes the relevance of this research in seeking effective ways of how low carbon can be integrated into strategic design. The concept of low carbon is not easy to define and is often perceived as merely a method for the reduction of Greenhouse Gases (GHG) and carbon dioxide $\left(\mathrm{CO}_{2}\right)$ emissions [10] as well as a way to minimise energy and transport gas emissions. For the scope of this paper and in relation to the landscape, the term is used to indicate a new lifestyle, and deals with environmental security in various aspects from energy to design and from concept to materiality. The research acknowledges that low carbon is a flexible concept and it can be interpreted in various ways depending on the project goals and cultural background.

Bulkeley et al. [11] state that "there is evidence of a shift in urban thinking on climate change as cities are taking a more strategic approach to climate change". Although carbon reduction is widely seen as a legitimate aim, it raises a range of questions related to how to achieve a smooth transition and an environmental friendly lifestyle that will reduce carbon emissions, as well as how such concepts can be evaluated based only on the numerical models and mathematical equations on which carbon is currently being assessed. Is the low carbon way of living defined only by carbon footprint and the carbon cycle process? Or do these terms still lack a broader interpretation, as Wiedmann and Minx [12] argued a decade ago? According to the position statement of the Canadian Society of Landscape Architects, "there is no uncertainty over climate change, there is only difficulty in predicting accurately by how much, and how soon will conditions change, and where will the impacts be first felt and hardest received" [13]. Latour, reflecting on human relationships with nature and our reaction to climate change, states "what could have been just a passing crisis has turned into a profound alteration of our relation to the world" [14]. Therefore, from a landscape perspective there are several indications that demonstrate the affiliation of climate change with spatial strategies. The key element here is that several environmental phenomena are having a far greater impact on the landscape, human life and nature, as a result of climate change. As the Intergovernmental Panel on Climate Change states, "Impacts from recent climate-related extremes, such as heat waves, droughts, floods, cyclones, and wildfires, reveal significant vulnerability and exposure of some ecosystems and many human systems to current climate variability" [15].

During recent decades, sustainable communities and infrastructure have begun to receive significant attention in the planning literature, highlighting the importance of low carbon development. Although some of the literature discusses spatial planning, 'plans' are generally considered either as a "product of the process or as a guide for promoting a sustainable community" [16]. It is encouraging that terms such as 'sustainability' and 'carbon' are starting to be linked with strategic schemes and planning; however, at the moment climate change is apparently seen principally as a 'technical problem' 
and the idea of low carbon is interpreted in relation to spatial development as a 'technical kit' that will mitigate or adapt to the challenge. The senior advisor for the 'Spatial and Environmental Quality' for the Room for the River programme (Netherlands), discussing the importance of concepts such as hydrological efficiency and ecological soundness in landscape schemes, explained that climate change is not something that people can immediately see and, therefore, they do not find it easy to understand (Van der Grift, Interview, 15 July 2015). In a way, we are still trapped in the single-sided view that the spatial interpretation of 'low carbon' is just about technological projects or identifying the best possible location to introduce renewable activities. As Van der Grift suggests, we have to find ways to engage with society and introduce the importance of environmental soundness in landscape projects.

One way to improve the understanding of what low carbon means for the landscape is to examine how climate change impacts on it and the whole planet. Not only are warmer temperatures, rising sea levels, and extreme climatic effects, including droughts and higher rainfall, more frequent and likely to affect the planet for centuries, but they all become concerns when designing, planning and managing our cities and landscapes in order to 'future proof' them. As the Town and Country Planning Association's 'Rising to the Climate Crisis' guide suggests, availability of information and a strong preparation of strategic and local development plans will assist in tackling climate change and improving resilience [17].

\subsection{Opportunities for Environmental Landscape Design}

This paper argues that the term 'low carbon' can be symbolic of behavioural change and a new lifestyle that promotes environmental, cultural, social, historic and economical sustainability through exploration and understanding of the land. All aspects of design and planning can mitigate the onset of a changing climate, protect our natural resources and support our communities in adapting to our changing conditions. Designers, landscape architects and planners work to accommodate both the needs of human society and the natural environment, respecting the cultural landscapes of the past, and planning sustainably for the future [13]. The designer can create a vision and interpret low carbon elements in ways that engage the user and promote a healthy and environmentally-sensitive way of living.

In terms of the importance of a changing climate, it is recognised that "there is no alternative for countries but to incorporate low carbon measures in their development policies. The reality of climate change demands it, and there are also clear benefits in pursuing such for policies" [18]. Torres and Pinho [19] emphasise that "climate change is a global threat but local and individual actions are essential to mitigate it", encouraging the development of low carbon policies on local and national scales. Even though most political arguments regarding low carbon and spatial quality are currently developed individually, there are a few examples linking them with landscape design. The landscape designer Steven Kamerling, who has started blending the concepts of landscape and carbon, states that "topics like water and ecology are covered by laws and procedures, which means they have to be considered when planning new developments. It would be good if sustainable urban design was also included in planning legislation and procedures" [20]. However, less is known on how low carbon and climate change ideas can be integrated into regional and strategic design and planning, compared to specific and more familiar topics such as ecology, food and water.

Experts and professionals can help reduce excess carbon emissions, based on informed and holistic consideration of the environmental issues and not just simplistically relying on enhancing the natural sources. The reality is that we cannot afford to design anything without considering the environmental and climate challenges, but for these designs to be truly low-carbon and sustainable they need to integrate cultural, social and historic elements that will engage the user and create positive memories as well as addressing environmental soundness [21]. The transition to a low carbon city or region should not simply be based on the reduction of emissions and the use of new technologies, but involves the creation of a place that covers nature and human needs with a minimum use of resources while offering the joy of social engagement, the knowledge of cultural characteristics and 
awakening memories of historic environments. A sustainable landscape is not merely a space that deals with the reduction of carbon, but a place where a symbiotic relationship between nature and humans is fully appreciated, leading to future proofing natural and cultural characteristics. The role of the designer and planner often relies upon the influence of decision makers, and this is much more important when it comes to considering climate challenges at a strategic level. Smith et al. [22] highlight that national and international development goals and priorities, policies and commitments play an important role when decisions are taken at a higher administrative level such as regional or national authorities. The Paris Agreement introduced on 12 December 2015, with the aim to "strengthen the global response to the threat of climate change", was one of the most significant examples of national and international commitments on the last decade and goals were introduced with a focus towards sustainable development [23]. Nikologianni [2] also explains how policies and legislation affect the decision making relating to a potential landscape development and, therefore, policy should consider early integration and early engagement of the low carbon and spatial quality ideas from the very beginning of a landscape development. For this to happen, though, such concepts would need to be thoroughly integrated at the vision stage and a 'tailor-made' project framework for each scheme would need to be created.

Observing and evaluating strategic landscape schemes across Europe that have developed pioneering ways of envisioning, processing, managing and delivering large-scale projects has resulted in the identification of key elements that impact on decision making for large-scale projects, recognition of the importance of an innovative structure in order to secure smooth delivery and the best practices that enhance sustainability and spatial quality in regional landscape-based schemes. Demonstrating how the selected pioneer case studies have generated innovative ways of dealing with the strategic scale based on the context of each country and how this affects the landscape infrastructure and the environmental scene, the paper now discusses the key elements of making climate change to drive strategic landscape design. As Stephenson [24] states, "presenting landscape as "space" has a long pedigree in assessment practice, but conveying its rich and messy place-values is still a rarity in practice". The interpretation of low carbon is often challenged, with practitioners, researchers and others questioning whether it is based on activities, lifestyles and voluntary behaviour change or in policy frameworks influenced by regulatory forces [25].

We identify a series of innovative steps that these strategic projects have followed, from establishing the vision, integrating design at an early stage, to the interaction of governance and public participation and the successful delivery with further outcomes for the regional or national planning process. In these case studies, the whole project process is conceptualised as an alternative to the common current project frameworks, resulting in large-scale schemes that effectively address environmental challenges, behavioural change and quality of space, highlighting the necessity of multi-disciplinary collaboration in order to address environmental challenges.

\section{The Importance of a 'Tailored' Project Framework}

It has been found that current processes often follow conventional frameworks, but we argue that the innovation is for the project framework to effectively combine a series of new concepts and ideas addressing environmental, spatial and cultural challenges, while embedding specific policies or legislation to secure their delivery, making it eventually a 'tailored' framework for a particular spatial development (so it is tailored to an area with its topographic and cultural characteristics as well as the project scope). Data extracted from the case studies presented below suggest that this tailored framework will integrate the elements of spatial quality, sense of place, low carbon and pictorial forms and is of critical significance in order to enhance the development of a narrative and to secure the extent to which these ideas will be implemented in the landscape scheme. However, the support of politics and institutions is essential for the successful establishment of such a mechanism.

This new way of thinking should make clear that the potential landscape schemes are not only planned to deliver a piece of infrastructure, but to create sustainable places and enhance environmental 
and societal needs, respecting the cultural aspects of the area. Several concepts and ideas have been identified and developed from the case studies examined. Their efficient and careful combination has resulted in new processes that can shape the project development and outcome. However, for this to be achieved a tailored and carefully designed project framework needs to embed in its structure and plan all the different concepts (e.g., low carbon) as well as the ways in which they may interact. Developing a sophisticated process for each individual scheme which integrates its conceptual and implementation goals played a major role in their successful implementation. The focus on how space is perceived and understood, a different way of "conceptualising and shaping the project", the interpretation of key ideas into policies and politics and the importance of early planning before the implementation and delivery of a large-scale scheme, are all techniques found at the pioneer schemes in Catalonia, The Netherlands and the UK and are considered important elements for a successful large-scale landscape project. As the lead landscape architect of the Room for the River project in Nijmegen explained, a governmental strategy that encourages integration of environmental and cultural aspects provides significant support to a project framework that attempts to introduce new ideas (Schouten, Interview, 20 July 2015). Hence, low carbon design should not be perceived as a technical proposition, but as a design project that integrates cultural, social and environmental characteristics and is supported by governmental policy or legislation.

In particular, a framework addressing project concepts and the actions needed for the development of a vision has the potential to affect governmental values as well as decision making, with a consequent impact on project delivery and outcomes. The pioneer schemes discussed below have developed individual project frameworks that suit their aims. This could not have been achieved without strong support from the government, the creation of new policies and, in some cases, legislation for the landscape projects. The contrast in their approaches forms a unique opportunity to extract knowledge from a wide range of successful strategies.

\subsection{Innovative Case Studies}

There are differences between the ways in which issues of low carbon, climate change and spatial quality are introduced into large-scale regional design around Europe. This paper demonstrates the impact on the landscape project process and how such issues are interpreted, communicated and implemented on a strategic scale. The engagement of legal entities and governmental parties that has been revealed for the Catalan, Dutch and British case studies is important: however, this engagement relates to significant funding for the projects, enhancing the interest in low carbon and climate change explored here. The governmental and political commitment to design quality and environmental stability at a national level is shown by both the economic and legal support provided, creating a political agenda relating to such key ideas for regional and local authorities as well as future national proposals. The case studies have developed their own meaning through the various conceptual ideas of the landscape projects, generating a richness of interpretations and processes to make a project develop successfully within the focus of environmental awareness, climate adaptation and sustainability. These ideas can be embedded on a strategic landscape scale, using techniques of local clarification, engagement with local stakeholders and adopting the variability in meaning that different cultures might have. Their international recognition by practice and academia, the swift development of policy in their countries, the various climate awareness outcomes based on public engagement and in some cases the recipient of design or infrastructure awards (Room for the River) account for the successful transition to low carbon-oriented landscape infrastructure. A key element where the case studies have used innovative techniques is the flexibility to work at different scales and interpret concepts and designs from an abstract to a detailed level.

The landscape strategies examined have demonstrated how a landscape vision can be delivered across various scales and the importance of design in such actions. Acknowledging that climate change does not stop at regional or national boundaries defined by humans, the case studies have impacted to a far greater scale than that to which each individual project initially belonged. Dealing 
with the regional, as well as the detailed scale and using landscape design as the key medium for the formation and the dissemination of the ideas, the overall achievement of these studies is that the benefits apply at a regional or national level. The case studies have developed policy and project frameworks and have multidisciplinary teams consisted of academics and professionals who deal with landscape architecture, design, engineering and policy. However, the purpose of this paper is not to compare them; each case study has demonstrated important elements in different parts of a successful integration of sustainable ideas (e.g., in legislation, climate adaptation, awareness, decision making) and, therefore, best practices from each of them are extracted. The timelines, presented by Tables 1-3, demonstrate that this is inherently an intricate and lengthy process and reveal the key steps for their establishment as these were conducted in each case and following the legislation for each country.

\subsubsection{The Netherlands Model Tailored Framework}

The Dutch case studies (Room for the River and the New Dutch Waterline) have developed specific processes, created dedicated teams and built tailored frameworks that integrate the needs and delivery processes of each of their innovative large-scale schemes. The Room for the River is a climate adaptation programme that was introduced as an alternative to traditional planning approaches and was intended to form a more sustainable way of dealing with increased rainfall and rising sea levels. It emerged from the serious flooding that affected The Netherlands in 1993 and 1995, which was the trigger for a change in the planning and management of the river catchment areas. It is a national-scale design strategy, ensuring a high level of protection against rising water levels in 34 locations across The Netherlands (Figure 1), while creating more recreational areas and strengthening the economy [26]. National and local governments as well as designers, scientists, water authorities and provinces joined forces with a 2.3 billion euro [27] landscape programme with the aim of demonstrating that making room for the river was a unique opportunity for The Netherlands to address hydrological efficiency while improving spatial quality. The Room for the River is the largest water construction project since the Delta Works [26], it has introduced nine different ways to create room for the river (e.g., floodplain excavation, water storage, depoldering) and has managed to bring to life planning documents creating 34 dynamic projects that support a low carbon transition while boosting the economy.

This endeavour was based on a tailored framework introducing dedicated teams (e.g., Quality-Team, designers, water management team) as well as policy transition, that has allowed for this scheme to be a prototype in The Netherlands integrating design, policy and communication in such multidisciplinary terms that this authorship considers them pioneering for such a scale. The continuous engagement and close communication between the project locations and the government, as revealed during the interview with the Senior Advisor on spatial quality for the Room for the River (Van der Grift, Interview, 15 July 2015), as well as the explicit decision to appoint a multidisciplinary team (Q-Team) that was chaired by a landscape architect, to advise on and evaluate key elements such as spatial quality, design, ecological and hydrological efficiency, has introduced new ways of work to strategic infrastructure projects [28]. The emphasis given to design is believed to be a key to the later progression of the programme, as was explained by the State Advisor of The Netherlands at the time. Designers and programme administration had close communication, with the former entitled to identify the most suitable locations, as well as being able to develop conceptual ideas to support the programme's overall vision (Sijmons, Interview, 13 July 2015). The crucial part that designers played in the 34 project proposals delivered significant solutions to water and climate problems as well as high-quality landscapes [27].

The main timeline and key actions of this programme are briefly described in the table below for the purposes of this paper, however it must be recognised that other actions also took place. 


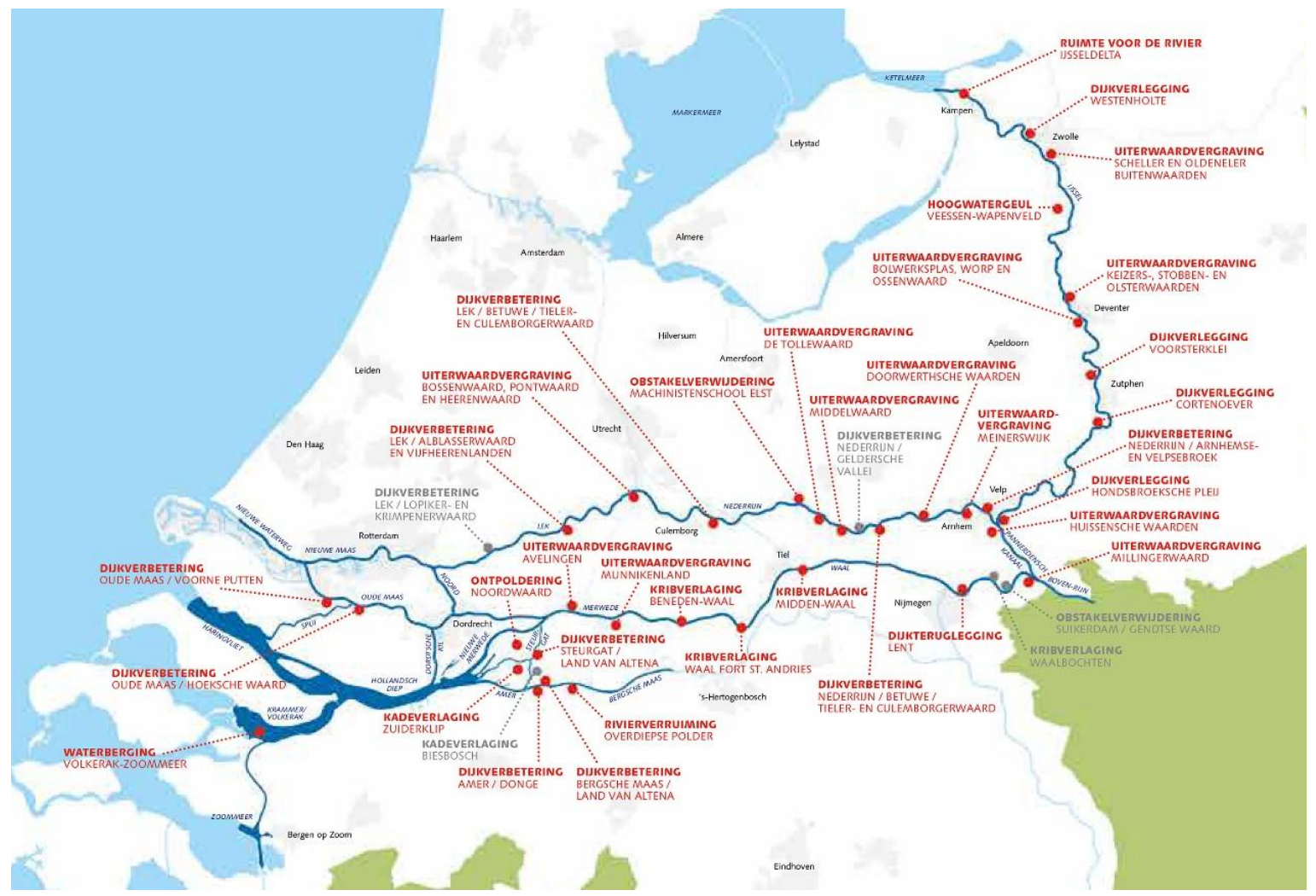

Figure 1. Map of the 34 locations of the Room for the River programme in The Netherlands. Source: Ruimte voor der rivier.

Table 1. Room for the River Programme timeline and key actions.

\begin{tabular}{cl}
\hline Date & \multicolumn{1}{c}{ Action } \\
\hline 1993 & Severe floods in The Netherlands \\
1995 & Severe floods in The Netherlands \\
1996 & Room for the River Policy by the Government \\
1997 & Fourth Water Management Memorandum/Royal Seal for water \\
$1998-1999$ & Study on the implementation of new policies \\
2000 & Room for the River through Dutch planning process \\
2003 & Start of regional process \\
$2003-2006$ & Plan phase/study \\
2006 & Spatial Planning Key Decision (SPKD) by Dutch cabinet \\
2006 & Approval of the Room for the River by the Dutch government \\
2007 & Planning decision for Room for the River formally put in operation \\
2007 & Beginning of work/Implementation \\
$2010-2011$ & Contract/Project development depends on the location \\
$2012-2016$ & Implementation and delivery of projects \\
2016 & Management \\
\hline
\end{tabular}

The 'New Dutch Waterline' is also a national landscape programme consisting of different fortifications across The Netherlands with approximately 45 forts, 600 bunkers, castles and citadels (Figure 2), that focuses on the preservation and revitalisation of the landscape infrastructure aiming for enhanced sustainability and quality of space. The fortification network was originally designed in the 19th century as a military defence system to enable controlled inundation through sophisticated landscape engineering, but was never used, leaving a historic and cultural landscape now in need of revitalisation. It is the largest defensive works in The Netherlands and is considered the largest national monument in the country. The New Dutch Waterline is one of the largest projects and the only national one mentioned in the Belvedere memorandum (1999), which aimed to formulate 
the Dutch policy on preserving cultural heritage [29] and in the Waterline's case also enhancing environmental aspects across the line. The vision of this scheme was to create new values for the fortifications, aiming to preserve and regenerate the existing structures while improving their visibility and accessibility to the existing landscape. The original design of the fortresses that enabled them to be inundated for strategic reasons was a challenge that need to be thought through and integrated in the design and the new uses proposed. The goal of this large-scale scheme was to preserve and revitalize the existing fortifications aiming to improve spatial quality, water safety, visibility and accessibility of the landscape. The water plays a major role in this scheme, however it is more related with awareness and education on water management as well as cultural acknowledgement rather than climate change adaptation. The successful implementation of the programme, together with the emphasis on sustainable development and landscape quality, has resulted in improvement of the existing historical landscape, creation of valuable public space and a unique identity for the Dutch landscape, and has led to nomination as a tentative UNESCO World Heritage site.

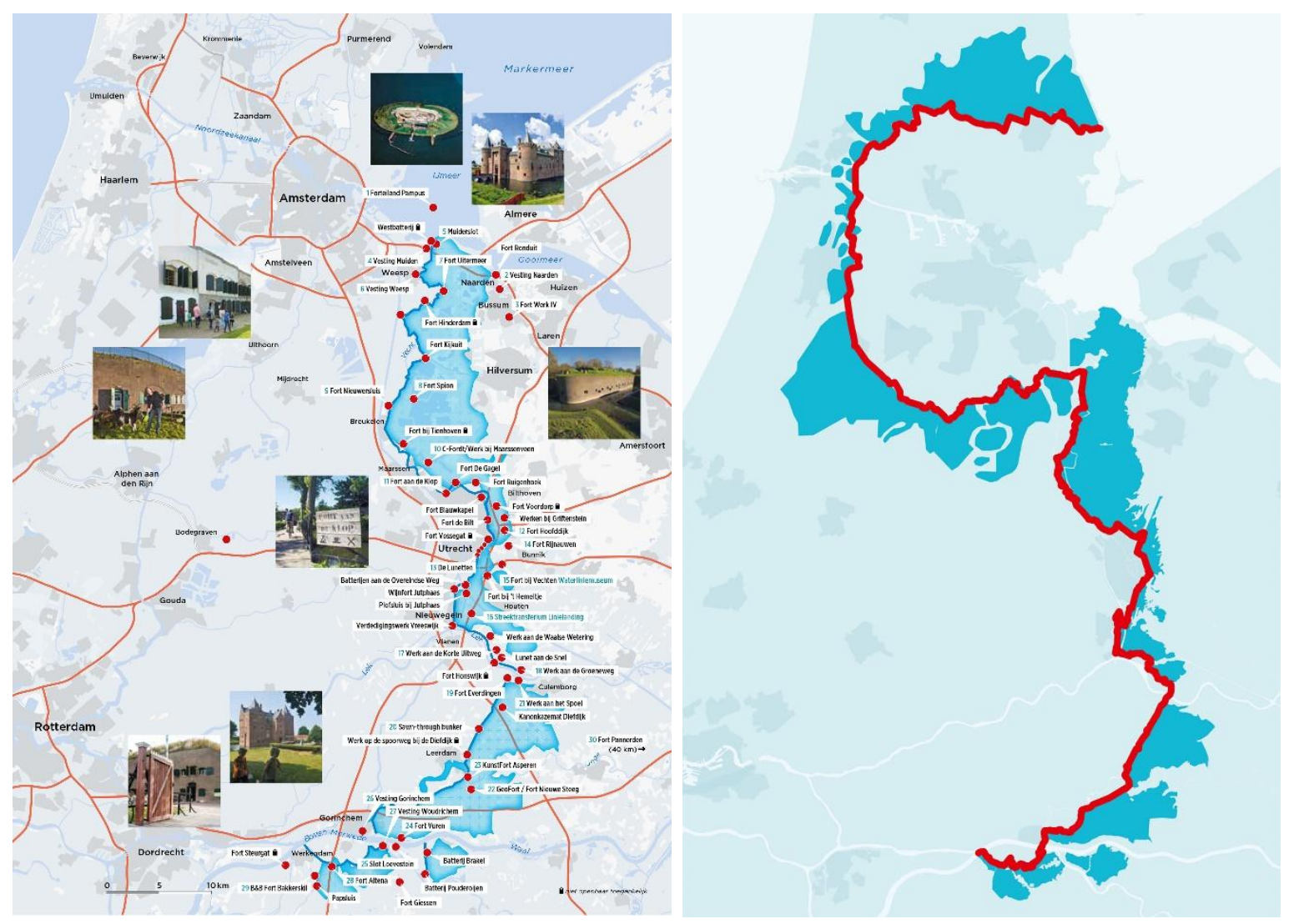

Figure 2. (Left) Map of the 'New Dutch Waterline' landscape scheme showing the defence line and the locations of the fortresses that have now adopt different uses. (Right) Showing the whole defence line, the locations around the fortresses that could have been inundated in the past and are now regenerated open areas. Source: public material—collected from Water Museum, The Netherlands.

The Dutch model has developed a specific project structure securing the goals of the project while integrating key ideas that the Project Vision had set. Both the Room for the River and the New Dutch Waterline strategic programmes had several teams with close communication links and very close connections to designers/landscape architects. According to the former First State Advisor for landscape architecture in The Netherlands, designers were involved from the early stages of the Room for the River programme and have played a key role in the development of the schemes (Sijmons, Interview, 13 July 2015). Various stakeholders such as national and local authorities, landscape architects, engineers, policy makers and public had formed groups with close 
communication during the programme's conceptual and implementation phase. The programme framework developed for the Room for the River (Figure 3) illustrates how the different parties communicate and collaborate in securing the goals set by the administration. It deals with the integration of conceptual ideas being developed across the different project locations and the way in which they can be secured during the landscape process. This programme is an important example of a low carbon concept at a strategic level for Europe, aiming to improve the overall environmental quality in the river region and having developed a method for the designs to be assessed (through the Q-team).

Key environmental, social and economic ideas were embedded at the early stages of the process, with the project goals of both the Room for the River and the New Dutch Waterline ratified in Dutch legislation. Especially for the Room for the River, a reporting system was created that had to be submitted for governmental and parliamentary approval [27]. The creation of dedicated teams responsible for delivery of environmental, cultural, and social values has also played a major role in successful delivery. The Dutch model is also a helpful example of how 'a design' can be implemented and how the landscape design in principle has improved environmental awareness and supported behavioural change.

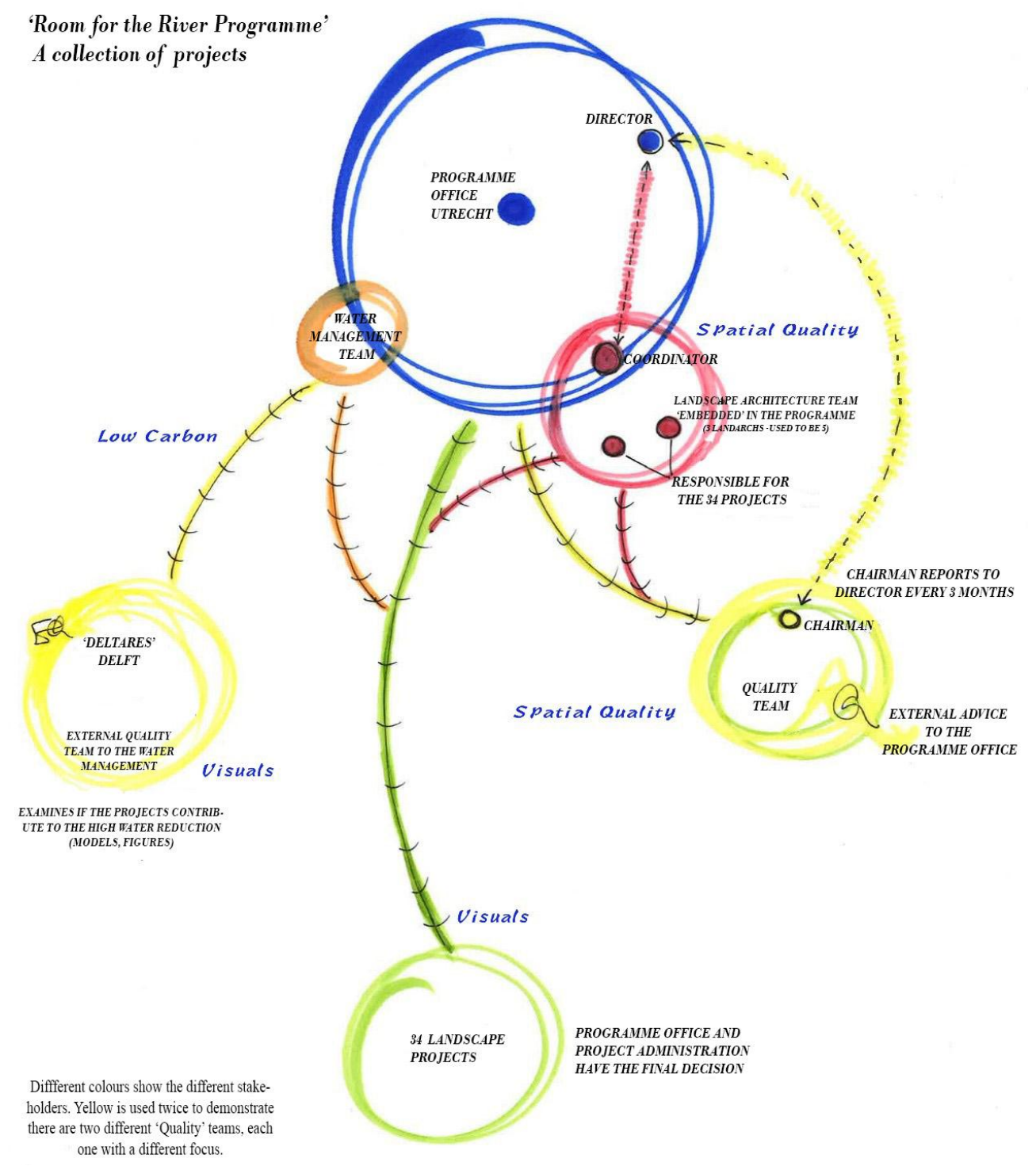

Figure 3. Programme framework for the Room for the River illustrating the main stakeholders participating in the scheme (author's diagram based on interviews with staff from the Room for the River). 


\subsubsection{The Catalan Landscape Observatory Model}

The Landscape Observatory acts on a regional as well as local scale. It is an advisory body on landscape issues for the government of Catalonia and Catalan society. It consists of a governing board, an executive committee, an advisory council and several administrative and technical groups. Originally established to implement the European Landscape Convention (ELC) [1], it has succeeded in bringing attention to the land and creating a landscape-oriented culture in the region, while continuing to support the application of the ELC. The Landscape Observatory works in a framework of sustainable development tailored for the Catalan society and landscape. It has a major impact in landscape awareness and regeneration at a regional scale and runs a number of local-scale projects. It is organised as a consortium and is included in the Act for Protection, Management and Planning of the Landscape in Catalonia [30]. The choice of the Landscape Observatory as a case study is based on its establishment integrating the ELC, as well as the strong impact it has on policy and legislation in the region.

Climate-related issues are being addressed through the monitoring of the Catalan landscape and the various local-scale projects that the institution coordinates. In terms of this paper's argument the case study has a stronger role on how a landscape-oriented institution impacts on decision making and governmental processes, creating a sustainable future for the landscape and the region. Through a series of catalogues, seminars, projects and public participation schemes introduced by the Landscape Observatory, there has been a significant change in the delivery of urban and regional infrastructure to such an extent that a public law protecting the landscape has been established in Catalonia [2]. One of the main instruments developed by the Observatory is the 'Landscape Catalogues' which aim to reveal the landscape character and raise awareness of the value of the landscape. Being formed by a unique territorial analysis which had never previously been conducted in such a scale and consistency for Catalonia (Sala i Marti, Interview, 18 June 2015), the Landscape Observatory has created seven Landscape Catalogues revealing 135 different landscape characters within the region (Figure 4). As described by Nogué et al. [31], the creation of the catalogues "placed the landscape, from a regulatory point of view, at the vertex of territorial planning in Catalonia" and the catalogues have been "an instrument for introducing the landscape in territorial planning in Catalonia, as well as in sectorial policies". Even though it is accepted that policy is not an easy area to deal with, progress has been made with the Catalan government to support the landscape awareness and promote sectorial initiatives that use the work of the Landscape Observatory as a basis or for the development of spatial guidelines. The support of the Catalan government has been essential to the development of the structure around the landscape idea. The current director of the institution suggested that "the Landscape Observatory has managed to give a new dimension to the government's policy and it also had a substantial response from the government in landscape issues" (Sala I Marti, Interview, 18 June 2015). The establishment and administration processes of the Landscape Observatory as well as key actions are presented in Table 2 below.

Through a variety of landscape projects aiming to sensitise Catalan society (Landscape Charter of Priorat, landscape plans of La Cerdanya, Landscape Catalogues, etc.), the Landscape Observatory has managed to enhance the received importance of the landscape. This has had a further result in the creation of new laws related to landscape protection, management and planning, as well as integrating key elements of design and landscape regeneration in policy. Acting on several smaller-scale locations in Catalonia, with projects that embed ideas on environmental design, preservation, restoration and landscape identity, the outcome has also been a better understanding of landscape and the emphasis on the need for new policy. Although these projects often have their own scope and goals, the Landscape Observatory holds the role of coordinator with the aim of generating knowledge about the landscape and exchanging good practices within Catalan society. The outcomes achieved by the Observatory model have resulted in the creation of documentation for the landscape as well as its active integration in policy and legislation for Catalonia. Governmental, political and financial support has also proven significant. 


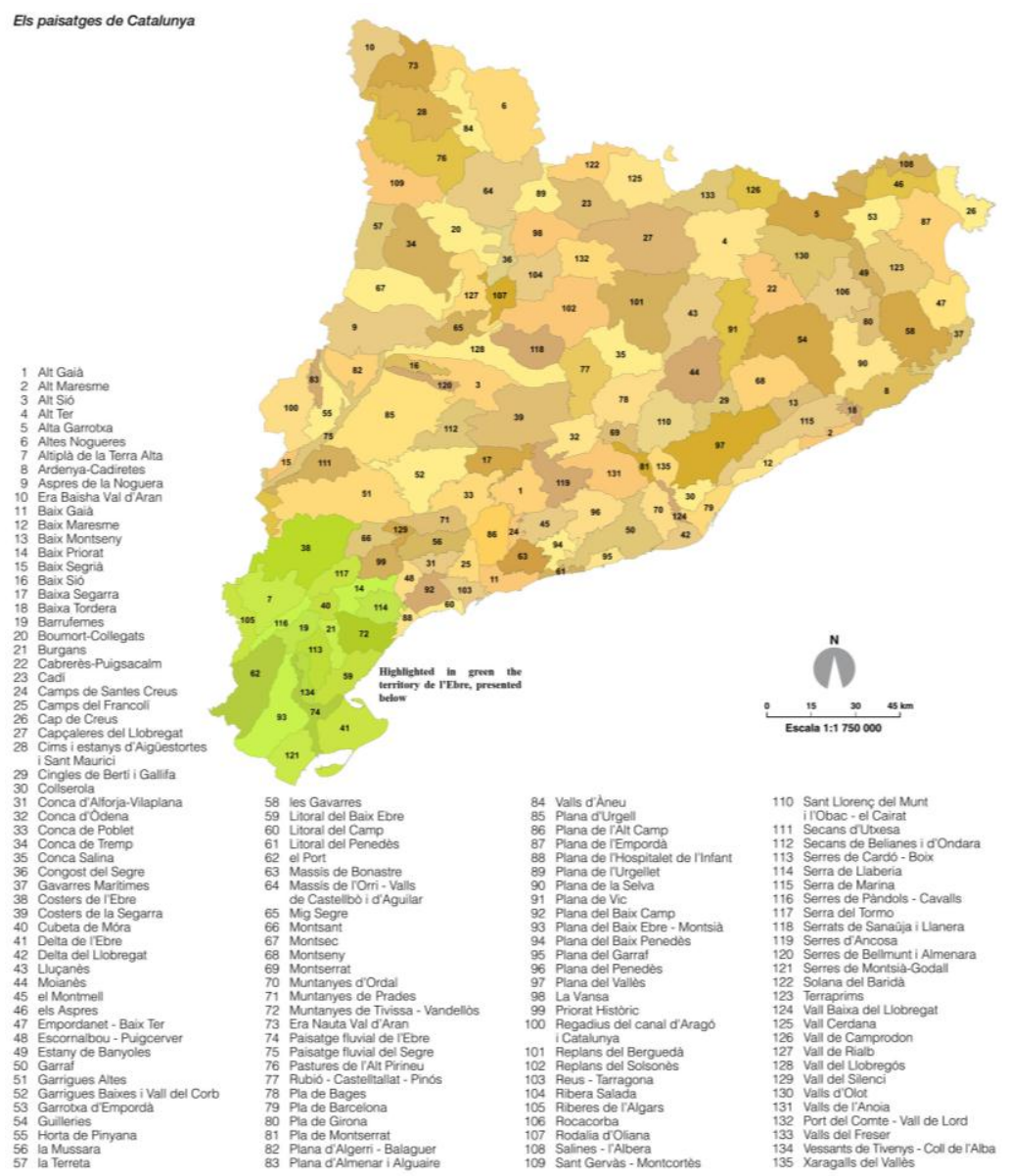

Figure 4. Els Paisatges de Catalunya. The image identifies the 135 different landscape types of Catalonia characterised by the Landscape Observatory. Source: Landscape Catalogue de l’Ebre, p. 29.

Table 2. Establishment of the Landscape Observatory and key actions.

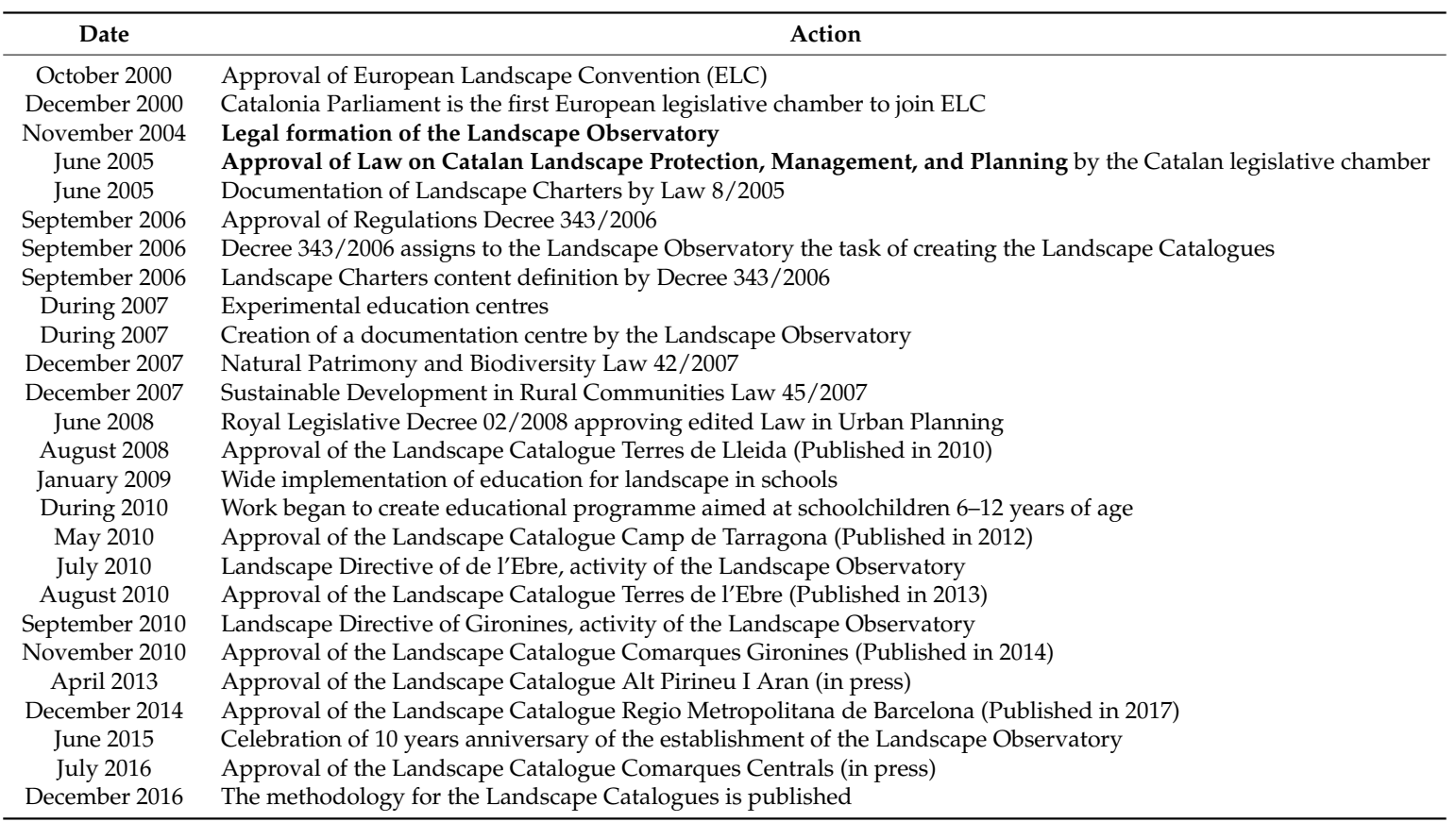




\subsubsection{HS2LV Model; A Design-Led Approach for Sustainability}

The High Speed 2 rail line (HS2) and HS2 Landscape Vision (HS2LV) projects were used to investigate ideas that will transform the English Midlands region. Both have now concluded their early conceptual stages and are moving towards design and implementation; hence this paper only presents a fraction of their development. HS2 is one of the largest traditional railway projects in the UK, while HS2LV is a research project that offers an alternative to this proposal looking at environmental strategies, spatial quality and the social and cultural characteristics of the West Midlands.

HS2 is a planned high-speed railway that through Phases 1 and 2 aims to link London, Birmingham, East Midlands, Leeds, Sheffield and Manchester. It has been described as a major engineering attempt of our times with budget estimates varying from $£ 55$ bn to $£ 80$ bn $[32,33]$ and is proposed to be an important step in Britain's economic development [32,33]. Due to existing project structure and policy, HS2 was initially going from the macro scale of the scheme right down to the very detailed level. HS2LV proposes to widen the conceptual and territorial scope of the high-speed project introducing a sustainable landscape-based way of thinking. It aims to transform a linear engineering and technical project-such as HS2 —into a comprehensive approach attracting local, regional and national interest. Using HS2 Ltd. to help build a landscape vision for the whole region, HS2LV is a landscape-led approach that has been developed to examine how it could act as a social and economic catalyst for the area. It proposes to put the landscape at the core of development, expanding the conceptual agenda as well as the territorial scope of the engineering project with the aim of giving value to the landscape and the region. The initial contradiction between the plans created for an engineering project and the HS2LV proposal for the establishment of a "symbiotic relationship between the landscape" [34], has led to its selection as a case study. Through a series of conceptual drawings and maps HS2LV has demonstrated that a narrative and a strong design concept for low carbon lifestyle will benefit the implementation of the engineering scheme and engage the community. The HS2LV drawing (Figure 5) managed to give a series of exciting possibilities for the region, without micro managing specific spots and areas. Therefore, the strengths of this case study in relation to sustainable landscape development are based on presenting land values, cultural and social characteristics and enhancing economic stability, through a design-led approach that will then lead to a stronger low carbon culture and landscape. The opportunity to illustrate 'fragile' concepts such as low carbon landscape or an environmentally friendly development through a design-oriented project framework has resulted in the recognition of these concepts and their integration to the scheme.

As the HS2 national infrastructure project is still under development, the framework model is currently established. The first stages of the HS2LV have demonstrated how a landscape approach can impact on the perceptions of politicians, decision makers and the public, however, some information is not yet widely available. Table 3 gives the HS2 and HS2LV main timeline and key actions to date, although there have been more actions in both projects.

\subsection{Shaping the Project}

Based on the best practices extracted from the case studies, we suggest that a 'tailored' project framework forms a viable and productive alternative to current practices and conventional thinking that often challenge sustainable development. It is a sequence of processes also referred to as 'shaping the project' that need to be established and introduced to all the major infrastructure schemes. Such administrative frameworks can develop on a strategic scale (see examples of the Landscape Observatory and the Room for the River) and form a significant part of decision making, securing the way in which high quality elements (such as spatial quality and sense of place) and climate focused ideas can be spatially implemented. Van den Broeck [35], discussing administrative processes and policies, has suggested that "it is a challenge to develop a new kind of 'frames' and a new way to use them for judgement and decision making aiming at spatial quality, however these frames are meant to ensure legal certainty". The pioneer landscape schemes have established ways to integrate the concepts of quality and sustainability through the different stages of the planning process, however 
different 'frameworks', 'structures' or methods to 'shape a project' are expected to develop depending on the occasion or the cultural context of the region. Such innovative projects are challenging the current processes, although they are proof that sustainable regional design needs a multidisciplinary approach linked by strong ideas.

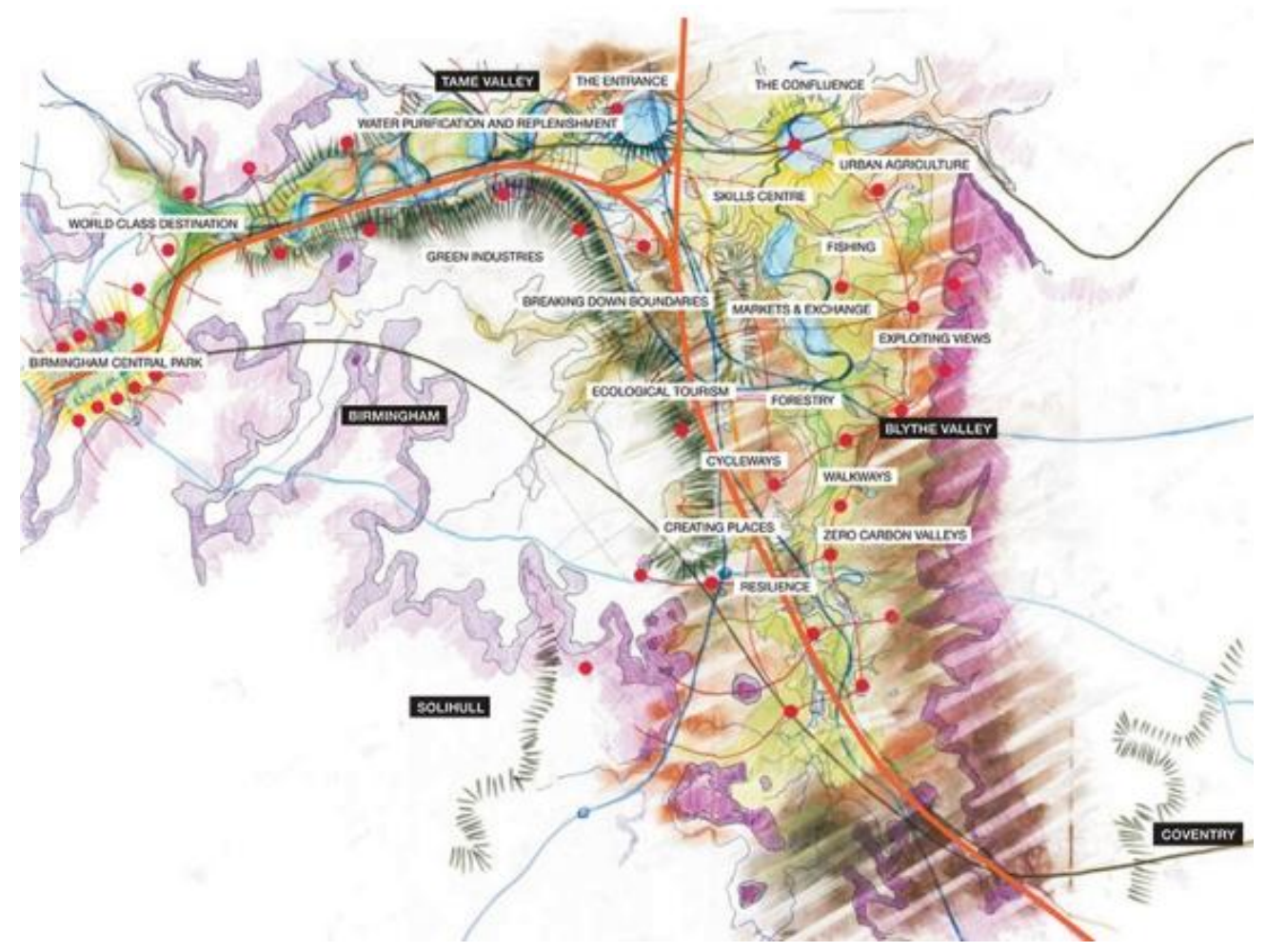

Figure 5. Conceptual drawing created to reveal the landscape identity of the West Midlands and illustrate an iconic landscape for HS2LV proposal in the route between London-Birmingham. The drawing illustrates the railway line, the valleys and environmental areas of the region as well as the high points with significant views. Source: Kathryn Moore personal archive.

Table 3. Hs2 and HS2LV main timeline and key actions.

\begin{tabular}{cl}
\hline Date & \multicolumn{1}{c}{ Action } \\
\hline January 2009 & Government established HS2 Ltd. to examine the case of a new high-speed line \\
March 2010 & HS2 report and supporting studies is published with preferred routes \\
March-June 2010 & Government commences a consultation on Exceptional Hardship compensation scheme \\
May 2010 & Urgent review request of the proposed route by the Secretary of State \\
December 2010 & Government publishes a revised HS2 route \\
February-July 2011 & Department of Transport to undertake a national consultation \\
January 2012 & Government proceeds with HS2 \\
May 2012 & Meetings for HS2LV are initiated \\
October 2012 & Public consultation \\
November 2012 & HS2LV work is undertaken at Birmingham City University \\
January 2013 & Announcement of the initial HS2 phase \\
May 2013 & Consultation on Environmental statement-Phase 1 \\
July 2013 & Launch of Phase 2 \\
October 2013 & House of Commons votes for the Preparation Act \\
November 2013 & The Queen approves the Preparatory Act for HS2 \\
End 2013 & Introduction of Hybrid Bill for HS2 \\
March 2014 & MPs vote on the 'principle' of HS2 \\
2015 & Target date for Royal Assent of HS2 \\
March 2015 & Chair of Design Panel appointed \\
October 2015 & Formation of Design Panel for HS2 \\
February 2017 & HS2 Received Royal Assent Act 2017 c.7 \\
Late 2018 & Ground work has started in various locations \\
\hline
\end{tabular}


Observations made during the case studies suggest that at the strategic scale, the concepts of low carbon and spatial quality often equate to other qualities, making complex ideas more tangible. For example, the Room for the River programme equates low carbon with hydrological efficiency and spatial quality with aesthetic meaningfulness (Sijmons, Interview, 13 July 2015), while the Landscape Observatory associates such ideas with landscape awareness and public engagement (Pere Sala, Interview, 18 June 2015). In the case of HS2, this interest is demonstrated by relating to the concepts of landscape identity, sustainability and wildlife [2] (HS2 Design Vision) and was enhanced by the interest attracted to HS2LV [2].

The UK National Planning Policy Framework (NPPF) states that "planning policies and decisions should play an active role in guiding development towards sustainable solutions, but in doing so should take local circumstances into account, to reflect the character, needs and opportunities of each area" [36]. Having a governmental strategy encouraging integration of 'fragile' concepts, as happened with the hydrological efficiency and spatial quality concepts in the Room for the River or the landscape character in the Landscape Observatory, is beneficial for their delivery. As the lead landscape architect of the Nijmegen project (one of the Room for the River locations) explained, "it was great that they [governmental institutions] had already the focus on a national level on the spatial quality so we could talk about it easier [in the Room for the River programme]" (Schouten, Interview, 20 July 2015). Best practices extracted from the case studies suggest that it is significant for key elements to follow a logic sequence developed by a vision and be addressed at all stages of the project framework. It is simply insufficient to link them to a policy or embed them in the structure of a framework without any supportive elements or concept to follow. It is important to create synergies aiming to achieve the same outcomes in the best possible way.

\section{Discussion: Key Elements of Successful Delivery}

A number of key elements that relate to the successful delivery of a strategic landscape scheme have been identified. The most significant are: The establishment of a strong vision, early integration of key ideas (e.g., low carbon, spatial quality), alignment with climate change and environmental challenges through all stages, the development of a tailored framework unique for its location, the importance of policy and governance, an implementation plan to engage with the narrative, a multidisciplinary team, good links of communication within the team, stakeholder collaboration and engagement, as well as the impact of design as a communication tool [2]. This paper focuses on the importance of a tailored project framework and the support of governance and legislation to the integration of sustainable elements into a landscape scheme.

\subsection{Project Framework: Support on Delivery}

An effective framework should be able to support the project through to its implementation. Administrative processes often struggle towards the project delivery stages, either with the initial vision fading or not following through the required stages of a scheme, resulting in a very different spatial outcome compared to that set out by the initial concept. As Klijn et al. [28] state, 'a worry which cannot be taken away yet, however, is whether the spatial quality 'promised' by the designs will actually be delivered during their implementation'. Therefore, we emphasise the importance of shaping a strategic scheme in a way that not only suits the mentality, culture and topography of the area, but also delivers the vision and intangible elements proposed by its designers, such as environmental solutions and sense of space.

The UK Design Council states that "the importance of design considerations in nationally significant infrastructure projects was set out in National Policy statements" [37], however, there are few examples on a large scale to date. It also adds that "Nationally Significant Infrastructure Projects (NSIPs) must make design an integral part of their planning process and demonstrate that good design and the concerns of communities and stakeholders have been taken on board in the planning process" $[37,38]$. Therefore, suitable means of combining the different concepts and their 
effective use during the project development is considered new and necessary for a successful delivery. The clarity of concepts and effective methods of communication introduced through the tailored project framework are important indicators of the extent to which key elements are likely to be embedded in the project process as well as the quality of their delivery. Even when a project framework is very dynamic in the establishment of concepts, such as landscape vision, landscape identity, sense of place, quality and environmental sustainability, it is important to embed a well-thought through and appropriate visual representation during all stages as, for example, was shown on Figure 5 for HS2LV, and in several scales (e.g., strategic, local). In that case, as the UK Design Council clarifies, an integral part of the scheme which counts for spatial understanding and communication will be secured, being able to act as a reminder of the vision and support project delivery.

The importance of design and visual representation at the project structure level has also been highlighted by Klijn et al. [28] who propose that "the designer in the team has a position in equilibrium to that of the engineers, and not as a subordinate". This was also highlighted by the State Advisor of the Dutch case studies, who explained that designers had a role from the very beginning of the Room for the River programme, whilst the examination for potential 'project areas' was through design (Sijmons, Interview, 13 July 2015). Even though design comes to play at some stage of the projects, the innovation for the Room for the River was its key role in the scheme from the earliest stages, giving the opportunity to the designers to reveal all the underlying elements of certain landscapes, such as historical, cultural and environmental strengths and weaknesses and, therefore, using design to form the plans for the infrastructure development.

\subsection{Government Engagement and Policy: Support on Delivery}

Overall, the establishment of a project framework that addresses the needs of each project individually is considered necessary, but it requires explicit support from policy and governmental legislation in a broader scale. A common governmental agenda and European or international legislation is believed to be important for the establishment of the project framework as the driving force in strategic schemes. This research suggests that a different way of delivery or a tailor-made project framework needs to be in place; however, it also acknowledges the fact that policy and legislation are extremely helpful in large scale design and planning.

In the case of the Landscape Observatory the institution has improved the understanding of the landscape and highlighted its importance, bringing it to the fore of infrastructure development and natural preservation. In addition, the framework structure consisting of several smaller individual projects has been a "source of inspiration for the birth of new local strategies" as Nogué et al. [31] state. The work of the Landscape Observatory has not only created a new mentality around landscape but has also changed policy in Catalonia.

The Netherlands case study has also highlighted that governmental support has been essential at the national-scale projects of the Room for the River and the New Dutch Waterline. The emphasis put by the Room for the River programme to create dedicated teams commissioned to deal with certain aspects of the project (e.g., Q-Team, Water management team), with the support of the government, demonstrates that a strategic scheme often needs top-down support as well as bottom-up engagement to be successful. In the Room for the River, the main goals of the programme (water safety and spatial quality) were given a legal basis when the national authorities formally embedded them within a national Key Decision on Spatial Planning Act [28]. It is argued that integrating key ideas of a strategic scheme in a legal form has assisted their implementation and delivery, while at the same time it has given 'moral permission' to the dedicated teams to negotiate and insist on their delivery [2], as stated by the lead landscape architect of Nijmegen who explained that they were flexible to pressure on spatial quality because it was a governmental requirement (Schouten, Interview, 20 July 2015).

Early signs of such activities have been observed at the HS2 scheme, where, even though it is still in progress, the interest for HS2LV and environmental characteristics has led to the creation of a design vision and a Design Review Panel that is authorised to evaluate the individual schemes. 
This research suggests that policies in landscape strategies need to be seen in a broader context that interacts with the project framework as well as the support of the national and regional government. It is only when "landscape design and related planning, policy and management activities may be used to intervene to bring aesthetic and ecological goals into closer alignment" [38] that key concepts such as environmental stability, examined by this paper, can be successfully delivered in regional landscape projects. Therefore, the continuous support of both the national and local government from the beginning and during the conceptual development and implementation of a strategic landscape scheme, together with new policy, is strongly recommended in order to achieve a sustainable landscape scheme.

\section{Conclusions}

The certainty of climate change and the increased likelihood of extreme climatic phenomena are now widely acknowledged among professionals and politicians. Assessing the most effective adaptation or mitigation methods and introducing key steps towards sustainable landscape design may vary between different countries, projects and cultures, however, they often employ the same principles. Due to the complexity and uncertainties involved, there is no alternative to the continuous examination of such phenomena and the creation of contemporary strategies that offer a multidisciplinary approach.

The schemes examined during this research demonstrate that, in cases where the idea of landscape is embedded in the vision of the infrastructure development (e.g., Room for the River), the schemes are more likely to have an environmentally successful outcome. Strategic landscape design and planning can play a major role in various elements. The use of geographic and topographic knowledge (e.g., Landscape Catalogues by the Landscape Observatory), nature, design methods and techniques can, to a certain extent, address environmental challenges and result in successful landscape strategies. Design and planning can also offer inspiring visions for future developments as generated by the HS2LV, which will spread awareness on the landscape and the low carbon transition as well as engage with the public and impact on behavioural change. One of the key suggestions of this paper is for the landscape to be considered as the way to enhance local identity and future-proof any development and, therefore, it needs to be considered in every project no matter what the scale. Each of the case studies has demonstrated that their specifically developed frameworks with a focus on the landscape idea, cultural and environmental characteristics have produced a positive outcome compared to previous projects following the 'conventional' approach.

Delivering a low carbon and sustainable landscape strategy is a matter of several elements. The selection of the right multidisciplinary people, with an interest in collaborating and creating new ways of dealing with such issues, is highly significant. The effort and time needed to put together a unique framework that integrates all the key factors of the proposed plan and at the same time sketches a vision for the area is a necessary investment. A deep understanding of the specific landscape and the impact any climate conditions might have for nature and humans is sometimes neglected in practice, however, the outcomes of this research gathered by the Landscape Observatory and its work in the Landscape Catalogues have brought to light significant evidence of its importance.

The proposed framework should clearly have a landscape focus and secure fragile ideas, such as low carbon in order to support the successful delivery of an environmental landscape scheme. A sophisticated, well-thought out and inclusive structure needs to be in place, in order to manage regional landscape strategies successfully, from concept to the implementation phase. Therefore, this paper suggests that low carbon design is not a technical proposition, but a broader landscape design approach which integrates social and cultural characteristics and can be supported by policy and legislation.

The vital role that governance and policy play in the establishment of such a tailored framework, as well as the opportunity given to the professionals to pressurise for specific outcomes, has been demonstrated in this paper. Governmental support not only assists in the integration of climate change and design ideas in a strategic framework, but also results in innovative solutions that have a long-term 
environmental vision by allowing the experts to work to the best of their knowledge and ability without being pressurized by particular interests of specific project stakeholders. A recommendation, policy or legislation has a tremendous impact on the decision making, and when it comes to the way in which environmental challenges are addressed it can be the main factor separating a future-proofed landscape-based regional strategy from another conventional engineering project.

Author Contributions: The corresponding author of this document, A.N., has conducted the research, fieldwork and formal analysis for this paper, while the authors K.M. and P.J.L. have supported with conceptualization, writing-review, editing and supervision.

Funding: This research has received funding support by EIT CLIMATE-KIC. The funders had no role in the design of the study; in the collection, analyses, or interpretation of data; in the writing of the manuscript; or in the decision to publish the results.

Acknowledgments: The authors want to thank EIT Climate-KIC, which has supported this research throughout, as well as all the stakeholders at the Room for the River, the New Dutch Waterline, the Landscape Observatory and HS2 Ltd.

Conflicts of Interest: The authors declare no conflict of interest.

\section{References}

1. Council of Europe. European landscape convention. Florence Eur. Treaty Ser. 2000, 176, 20.

2. Nikologianni, A. The Role of Low Carbon, Spatial Quality and Drawings in Landscape-Based Regional Strategies. Ph.D. Thesis, Birmingham City University, Birmingham, UK, 2017.

3. Cosgrove, D.E. Social Formation and Symbolic Landscape, 2nd ed.; The University of Wisconsin Press: Madison, WI, USA, 1998; 293p.

4. Shannon, K.; Smets, M. The Landscape of Contemporary Infrastructure; NAi Uitgevers/Publishers Stichting: Rotterdam, The Netherlands, 2010.

5. Bélanger, P. Is landscape infrastructure? In Is Landscape ... ? Essays on the Identity of Landscape; Doherty, G., Waldheim, C., Eds.; Routledge: Abingdon, UK, 2016.

6. Nefs, M. Blind Spot; Metropolitan Landscape in the Global Battle for Talent; Vereniging Deltametropool: Rotterdam, The Netherlands, 2016; 128p.

7. Bélanger, P. Landscape as infrastructure. Landsc. J. 2009, 28, 79-95. [CrossRef]

8. Meijsmans, N.; Beelen, K. Designing for a Region; Sun Academia: Amsterdam, The Netherlands, 2010.

9. United Nations. Adoption of the Paris agreement. In Proceedings of the United Nations Framework Convention on Climate Change (UNFCCC), Paris, France, 30 November-11 December 2015; pp. 1-32.

10. Yuan, H.; Zhou, P.; Zhou, D. What is low-carbon development? 2010 International Conference on Energy, Environment and Development-ICEED 2010. Energy Proced. 2011, 5, 1706-1712. [CrossRef]

11. Bulkeley, H.; Castan Broto, V.; Hodson, M.; Marvin, S. Cities and the Low Carbon Transition; Routledge: London, UK, 2011; pp. 24-27.

12. Wiedmann, T.; Minx, J. A definition of 'carbon footprint'. In Ecological Economics Research Trends; Pertsova, C.C., Ed.; Nova Science Publishers: Hauppauge, NY, USA, 2008; pp. 1-11.

13. CSLA. CLIMATES/ADAPTATIONS/LANDSCAPES—Landscape Architects Lead Climate Conscious Design and Planning; Canadian Society of Landscape Architects: Ottawa, ON, Canada, 2014.

14. Latour, B. Facing Gaia: Eight Lectures on the New Climatic Regime, English ed.; Polity Press: Cambridge, UK, 2017.

15. IPCC. Summary for policymakers. In Climate Change 2014: Impacts, Adaptation, and Vulnerability. Part A: Global and Sectoral Aspects. Contribution of Working Group II to the Fifth Assessment Report of the Intergovernmental Panel on Climate Change; Field, C.B., Barros, V.R., Dokken, D.J., Mach, K.J., Mastrandrea, M.D., Bilir, T.E., Chatterjee, M., Ebi, K.L., Estrada, Y.O., Genova, R.C.B., et al., Eds.; Cambridge University Press: Cambridge, UK, 2014.

16. Conroy, M.M.; Berke, P.R. What makes a good sustainable development plan? An analysis of factors that influence principles of sustainable development. Environ. Plan. A 2004, 36, 1381-1396. [CrossRef]

17. TCPA. Rising to the Climate Crisis-A Guide for Local Authorities on Planning for Climate Change; Town and Country Planning Association: London, UK, 2018. 
18. Mulugetta, Y.; Urban, F. Deliberating on low carbon development. Energy Policy 2010, 38, 7546-7549. [CrossRef]

19. Torres, M.; Pinho, P. Encouraging low carbon policies through a Local Emissions Trading Scheme (LETS). In Proceedings of the 45th ISOCARP World Congress on the topic "Low Carbon Cities", Porto, Portugal, 18-22 October 2009.

20. Meijer, M.; Adriaens, F.; van der Linden, O.; Schik, W. A next step for sustainable urban design in The Netherlands. In Proceedings of the 45th ISOCARP World Congress on the topic "Low Carbon Cities", Porto, Portugal, 18-22 October 2009.

21. Lamming, R.; Faruk, A.; Cousins, P. Environmental soundness: A pragmatic alternative to expectations of sustainable development in business strategy. Bus. Strateg. Environ. 1999, 8, 177-188. [CrossRef]

22. Smith, A.J.; Flowers, P.; Larkin, M. Interpretative Phenomenological Analysis Theory, Method and Research; SAGE Publications Ltd.: London, UK, 2009.

23. United Nations Framework Convention on Climate Change. The Paris Agreement; UNFCCC: Paris, France, 2015; pp. 1-16.

24. Stephenson, J. The dimensional landscape model: Exploring differences in expressing and locating landscape qualities. Landsc. Res. 2010, 35, 299-318. [CrossRef]

25. Feliciano, M.; Prosperi, D.C. Planning for low carbon cities: Reflection on the case of Broward County, Florida, USA. In Proceedings of the 45th ISOCARP World Congress on the topic "Low Carbon Cities", Porto, Portugal, 18-22 October 2009.

26. Zevenbergen, C.; Tuijn, J.; Rijke, J.; Bos, M.; Herk, S.; Douma, J.; Paap, L.R. Tailor Made Collaboration; A clever Combination of Process and Content; River, R.R.F.T., Ed.; Rijkswaterstaat: Rotterdam, The Netherlands, 2013.

27. Sijmons, D.; Feddes, Y.; Luiten, E.; Feddes, F.; Nolden, M. Room for the River; Safe and Attractive Landscapes; Blauwdruk: Amsterdam, The Netherlands, 2017; 288p.

28. Klijn, F.; de Bruin, D.; de Hoog, M.C.; Jansen, S.; Sijmons, D.F. Design quality of room-for-the-river measures in The Netherlands: Role andassessment of the quality team (Q-team). Int. J. River Basin Manag. 2013, 11, 287-299. [CrossRef]

29. Janssen, J.; Luiten, E.; Renes, H.; Rouwendal, J. Heritage planning and spatial development in The Netherlands: Changing policies and perspectives AU-Janssen, Joks. Int. J. Herit. Stud. 2014, 20, 1-21. [CrossRef]

30. Observatori del Paisatge. The Landscape Observatory. 2015. Available online: http://www.catpaisatge.net/ eng/ (accessed on 15 March 2015).

31. Nogué, J.; Sala, P.; Grau, J.I. The Landscape Catalogues of Catalonia Methodology. In Landscape Observatory Documents 03, 1st ed.; Landscape Observatory: Catalonia, Spain, 2016; p. 142.

32. Busby, M. HS2 may run fewer, slower trains to stay on budget and schedule. The Guardian, 2019. Available online: https:/ / www.theguardian.com/uk-news/2019/jan/13/hs2-may-run-fewer-slower-trains-to-stayon-budget-and-schedule (accessed on 7 February 2019).

33. Espiner, T. Is the HS2 rail project in trouble? BBC News, 2018. Available online: https:/ /www.bbc.co.uk/ news/business-46461606 (accessed on 7 February 2019).

34. Moore, K. HS2 Can Be Beautiful-Not a Blot on the Landscape; Birmingham City University: Birmingham, UK, 2013.

35. Van den Broeck, J. Strategic spatial planning and strategic projects. A transformative practice. In Proceedings of the 44th ISOCARP Congress, Dalian, China, 19-23 September 2008.

36. Ministry of Housing, Calgary. National Planning Policy Framework; Calgary Ministry of Housing Crown: London, UK, 2018; p. 76.

37. Design Council. A Design-Led Approach to Infrastructure; Cabe: Northampton, UK, 2012.

38. Gobster, P.H.; Nassauer, J.I.; Daniel, T.C.; Fry, G. The shared landscape: What does aesthetics have to do with ecology? Landsc. Ecol. 2007, 22, 959-972.

(C) 2019 by the authors. Licensee MDPI, Basel, Switzerland. This article is an open access article distributed under the terms and conditions of the Creative Commons Attribution (CC BY) license (http:/ / creativecommons.org/licenses/by/4.0/). 